\title{
Patterns of genetic variation in bud flushing of Abies alba populations
}

\author{
Georgeta Mihai ${ }^{(1)}$, \\ lonel Mirancea ${ }^{(1)}$, \\ Marius-Victor Birsan ${ }^{(2)}$, \\ Alexandru Dumitrescu ${ }^{(2)}$
}

\begin{abstract}
In the spring of 2007, 51 full-sib and six half-sib families of European silver fir were obtained through controlled and open pollinations from the same clones in a seed orchard. Genetic variation and parameters for bud flushing were determined in two progeny tests established in a nursery. The results indicate a high genetic control of bud flushing of European silver fir. Both the additive and the dominance genetic variances were major sources of genetic variation. The additive genetic variance was greater for open-pollinated than for full-sib progeny, representing $50-95 \%$ of phenotypic variance. Narrow-sense individual heritability estimates for control-pollinated progenies ranged from 0.14 to 0.64 , while the full-sib family heritability ranged from 0.09 to 0.40 . In the open-pollinated progenies, the values of individual and family heritability were higher than those in control-pollinated progeny and ranged from 0.50 to 0.95 for both. In both experiments, genetic parameters were higher for bud flushing at the beginning of the growing period than at later stages. The genetic correlations between bud phenology and growth traits were positive and significant in control-pollinated progeny but not significant in open-pollinated progeny. Positive significant correlations between control-pollinated and openpollinated progeny showed a maternal effect. Bud flushing was negatively correlated with geographic and climatic parameters of the site of parents' origin, accounting for $\mathbf{8 3 - 9 7 \%}$ of the total variation of this adaptive trait.
\end{abstract}

Keywords: Bud Flushing, Climatic Parameters, Correlations, Genetic Parameters, Genetic Variation, Silver Fir

\section{Introduction}

European silver fir (Abies alba Mill.) is one of the most important forest tree species in Europe, for both economic and ecological purposes. However, breeding programmes of European silver fir in many countries are less frequent compared with other species. In general, there are few provenance trials with a high number of provenances established in Europe and even less progeny trials. The reason why silver fir has not been considered a high priority species in breeding programmes is its capacity to regenerate naturally.

In Romania, the tree breeding programme started in the 1960s, and the European silver fir was one of the prioritised species. Breeding activities have focused on improving growth, wood quality and re- sistance to biotic and abiotic factors. Among abiotic factors, late spring frosts often cause injuries to young shoots of European silver fir, especially when the forest reproductive material is poorly adapted to local climate at the planting site. Frost injuries produce stem forking in coniferous species by killing the terminal shoot, which leads to an improper stem formation. The late frost injuries depend on the time of bud flushing and are related to the occurrence of severe frosts in late spring.

Genecology studies have shown that variation in the time of bud flush is a complex interaction among genetic characteristics of local sources and environmental conditions of the growing site (Dhar et al. 2015). Genetic variation and inheritance of bud flushing timing have been studied for many $\square$ (1) Marin Dracea National Institute for Research and Development in Forestry, Department of Forest Genetics and Tree Breeding. Bulevardul Eroilor nr. 128, Voluntari, Ilfov (Romania);

(2) Meteo Romania - National Meteorological Administration, Department of Climatology, Sos Bucuresti-Ploiesti 97, 013686 Bucharest (Romania)

@ Georgeta Mihai (gmihai_2008@yahoo.com)

Received: Dec 14, 2016 - Accepted: Jan 13, 2018

Citation: Mihai G, Mirancea I, Birsan M-V, Dumitrescu A (2018). Patterns of genetic variation in bud flushing of Abies alba populations. iForest 11: 284-290. - doi: 10.3832/ifor2314-011 [online 2018-04-13]

Communicated by: Mike Perks tree species, such as Douglas fir (Bailey \& Harrington 2006, Schermann et al. 1997), white spruce ( $\mathrm{Li}$ et al. 1993), European beech (Chmura \& Rozkowski 2002, Gomory \& Paule 2011, Von Wuehlisch et al. 1995), Norway spruce (Eriksson et al. 1978), European larch (Gauchata \& Pâques 2011, Worrall 2008), paper birch (Dhar et al. 2015) and Pinus species (Steiner 1979). Bud flushing has been shown to be under strong genetic control, and late bud flushing to be highly correlated with reduced spring frost injury (Aitken \& Adams 1997, Hannerz et al. 1999, Li \& Adams 1993).

In the case of European silver fir, high genetic variability in growth, phenology and morphological traits has been reported among provenances (Hansen \& Larsen 2004, Kerr et al. 2015, Mihai 2009, Vitasse et al. 2009). Progeny tests have revealed high amounts of genetic variation at the family level for growth and quality traits, and a significant potential for selection and breeding (Barzdajn 2010, Gagov et al. 2005, Mihai et al. 2014). To assess the genetic potential for selection within and among families, the level of genetic control of economic and adaptive traits must be determined ( Li et al. 1993). Although the association between bud flush dates and spring injury has been reported for some Abies species (Emerson et al. 2006, Jones \& Cregg 2006), there has been no study to assess the genetic control of bud flushing in European silver fir.

The phenology of bud flushing in forest 
species is fundamental for their survival and growth. Variation in the timing of bud flushing has implications in the susceptibility of genotypes to frost damage and may determine a variation of annual height growth (Li et al. 1993, Rweyongeza et al. 2010). Moreover, information on the genetic variation and inheritance of adaptive traits is extremely important in species breeding programme, both for the delineation of provenance regions and the production of high-quality timber. In this regard, bud flushing phenology is critical for decision-making on reforestation, particularly for the transfer of forest reproductive material, in order to maximise adaptability and wood production.

To address these problems, the objectives of this study were to: (i) investigate the genetic variation of bud flushing in two progeny tests of European silver fir created through controlled and open pollination at the nursery stage; (ii) determine and compare the genetic parameters of controland open-pollinated tests; (iii) assess correlations between bud flushing and growth traits; (iv) assess the relationships among variation in bud flushing and the geographic and climatic parameters of the site of parents' origin; and (v) evaluate the potential for selection and implications for breeding programmes.

\section{Materials and methods}

\section{Genetic material and mating design}

The study orchard of European silver fir is situated in the Adancata Forest District in the oak zone (latitude $47^{\circ} 42^{\prime} \mathrm{N}$, longitude $26^{\circ} 22^{\prime} \mathrm{E}$, elevation of $370 \mathrm{~m}$ a.s.l.) in northern Romania. The orchard is very well isolated and is composed of vegetative copies of 46 plus trees selected from four provenance regions (Parnuta et al. 2010). To maintain high genetic diversity in future generations, clones involved in both full-sib and open-pollinated families originate from all four provenance regions of plus trees (Fig. 1).

In the spring of 2007, 11 clones of European silver fir from the seed orchard were mated in a half-diallel design, resulting in 51 full-sib families out of 55 possible crosses. Open-pollinated seed from six of the 11 clones used in controlled crosses also were collected from the seed orchard.

The flowers were isolated in paper bags on 20-21 April 2007, shortly after the occurrence but prior to pollen dissemination. Pollination was performed with fresh pollen on 27-28 April 2007.

\section{Nursery design and assessment of bud flushing}

Both full-sib and open-pollinated seeds were sown in nursery beds for germination in autumn 2007. At the age of two years, the seedlings were planted in polyethylene bags filled with humus in a randomised complete block design with three replications in a single experiment in the Sinaia nursery, which is situated in the mountain beech zone of Romania (latitude $45^{\circ} 29^{\prime} \mathrm{N}$, longitude $25^{\circ} 59^{\prime} \mathrm{E}$, elevation $695 \mathrm{~m}$ a.s.l. Fig. 1).

The assessment of bud flushing was made in two consecutive growing seasons (2012 and 2013) by examining 14 seedlings per plot per family in each of three replications, both for full-sib and open-pollinated families. The bud flush survey involved recording only the terminal bud, as the lateral buds could be at a different stage, using a 5-point scale starting from $1=$ unbroken bud to $5=$ needles completely open and fully elongated (Ducci et al. 2012). This has simplified interpretation of the data by ranking the family means to a scale of $1=$

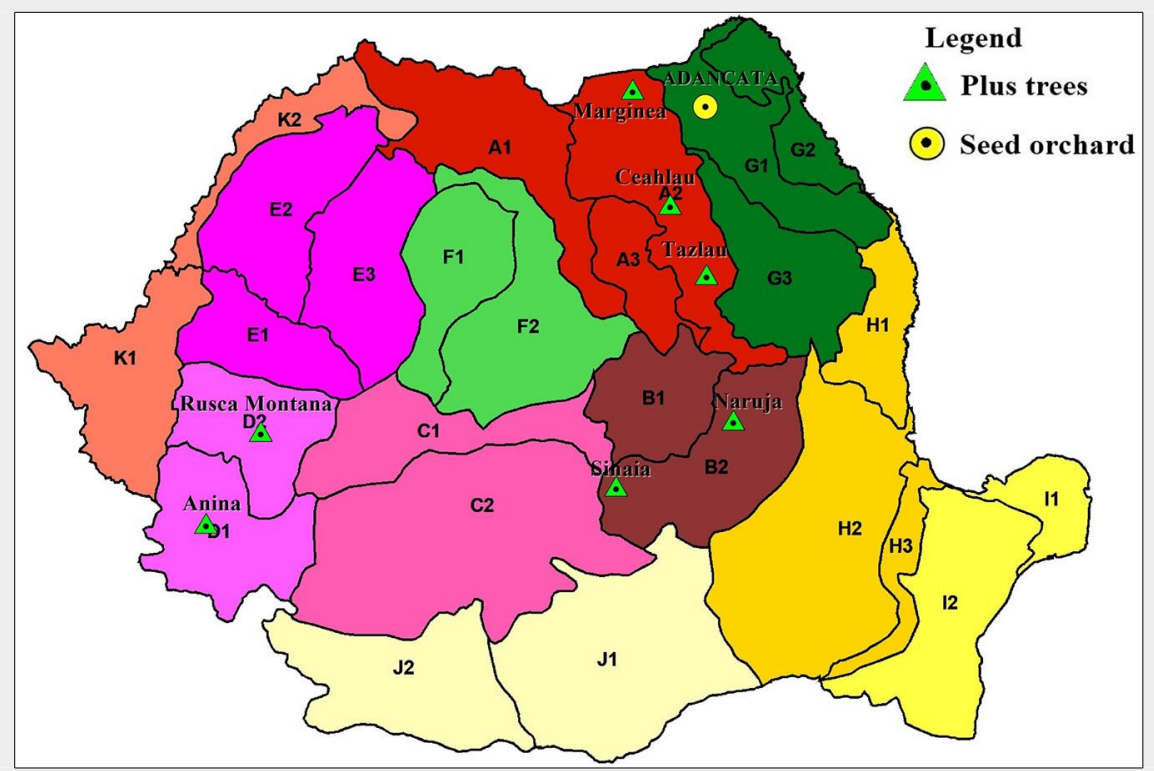

Fig. 1 - Location of the European silver fir seed orchard and tested populations (map of provenance regions taken from Parnuta et al. 2010). early to 5 = late. The observations were made in a single day with a periodicity of five days in 2012 and only once in 2013. Thus, in 2012 four evaluations were performed, starting at 30 April until 15 May, and in 2013 the assessment was made on 8 May. Accordingly, with the two sets of progeny generated by controlled crosses (CC) and by open pollination (OP), the following notations were used to refer to the different bud flushing evaluations:

- CC-I-2012, CC-II-2012, CC-III-2012, CC-IV2012: bud flushing score in the full-sib progeny of the first, second, third and fourth evaluations in the year 2012, respectively;

- CC-2013: bud flushing score in the full-sib progeny of the evaluation in the year 2013;

- OP-I-2012, OP-II-2012, OP-III-2012, OP-IV2012: bud flushing score in the open-pollinated progeny of the first, second, third and fourth evaluations in the year 2012, respectively;

- OP-2013: bud flushing score in the openpollinated progeny of the evaluation in the year 2013 .

In addition to bud flushing, growth characteristics were also measured. Results concerning the genetic variation and inheritance of growth characters at the nursery stage are reported in Mihai et al. (2014). To assess the relationship between bud flushing and growth traits, we have included in this study only the following traits: total height (in $\mathrm{cm}$ ) at the ages of 5 and $6(\mathrm{H}$ 2012, H-2013); current height increment (in $\mathrm{cm}$ ) at ages 5 and 6 (h-2012, h-2013); and root collar diameter (in $\mathrm{cm}$ ) at the ages of 5 and 6 (D-2012, D-2013).

For progeny tests, temperature and precipitation data were recorded using a logger installed at the nursery. Also, the climatic parameters at the site of the parents' origin were determined. We used six bioclimatic variables (based on temperature and precipitation data) calculated for the period of 1968-1977 from the ROCADA gridded daily climatic dataset (Dumitrescu \& Birsan 2015), a state-of-the-art homogenised climatic dataset throughout Romania with a spatial resolution of $0.1 \times 0.1^{\circ}$, covering the period of 1961-2013, for nine meteorological variables.

\section{Statistical analysis}

Individual tree data for CC and OP progenies were analysed separately using appropriate mathematical models for the each type of mating design.

\section{The full-sib progeny}

A half-diallel mating design was used (method 4 - Griffing 1956b), taking into account only direct crossings; reciprocal crosses and self-pollination were excluded. All effects were considered random for the estimation of variance components (model II, random - Griffing 1956a), since the tested trees were random samples from the parent populations. Three parents had 
1-2 missing crosses, for a total of four missing crossings in the entire experiment. However, according to $\mathrm{Wu} \&$ Matheson (2000), missing a few crosses in a complete half-diallel design does not significantly alter the hypothesis testing for the effects of replication, general combining ability (GCA) effect or specific combining ability (SCA) effect, and it does not significantly affect the relative GCA ranking of parents.

The statistical analysis used individual seedling measurements and followed the mathematical model (eqn.1):

$$
X_{i j k}=\mu+r_{k}+g_{i}+g_{j}+s_{i j}+e_{i j k}
$$

where $X_{\mathrm{ijk}}$ is the individual seedling observation, $\mu$ is the overall mean, $r_{k}$ is the effect of the $k^{\text {th }}$ repetition, $g_{i}$ is the GCA of the $i^{\text {th }}$ parent, $g_{j}$ is the GCA of the $j^{\text {th }}$ parent, $s_{i j}$ is the SCA of the $i^{\text {th }}$ and $j^{\text {th }}$ parents, so that $s_{i j}=$ $s_{\mathrm{ii}}$ and $e_{\mathrm{ijk}}$ is the random error associated with the $i j k^{\text {th }}$ seedling.

The model of variance analysis and expected mean squares are listed in Tab. S1 (Supplementary material). The analyses were based on plot means using the leastsquares method proposed by Schaffer \& Usanis (1969). Because data on individual seedlings were available, a separate analysis was performed to estimate the withinplot variance $\left(\sigma_{\mathrm{w}}^{2}\right)$.

It was assumed that epistatic components of genetic variance were negligible in the population examined. Therefore, GCA variance $\left(\sigma_{C C A}^{2}\right)$ was used as an estimator of the additive genetic variance and SCA variance $\left(\sigma_{S C A}^{2}\right)$ as an estimator of the dominance genetic variance, as in the following equations (eqn.2, eqn.3, eqn.4, eqn.5):

$$
\begin{aligned}
\sigma_{P}^{2} & =\sigma_{G}^{2}+\sigma_{e}^{2} \\
\sigma_{G}^{2} & =2 \sigma_{G C A}^{2}+\sigma_{S C A}^{2} \\
\sigma_{A}^{2} & =4 \sigma_{G C A}^{2} \\
\sigma_{D}^{2} & =4 \sigma_{S C A}^{2}
\end{aligned}
$$

where $\sigma_{P}^{2}$ is the phenotypic variance, $\sigma_{C}^{2}$ is the genotypic variance, $\sigma_{\mathrm{A}}^{2}$ is the additive genetic variance and $\sigma_{D}^{2}$ is the dominance genetic variance. Standard errors (SE) of variance components were estimated according to Becker (1967).

Based on genetic variances, the narrowsense individual $\left(h_{i}^{2}\right)$ and full-sib family heritability $\left(h^{2}\right.$ FS $)$ were calculated as follows (Xiang et al. 2003a - eqn.6, eqn.7):

$$
\begin{aligned}
& h_{i}^{2}=\frac{4 \sigma_{G C A}^{2}}{\sigma_{P h 2}^{2}}=\frac{4 \sigma_{G C A}^{2}}{2 \sigma_{G C A}^{2}+\sigma_{S C A}^{2}+\sigma_{p}^{2}+\sigma_{w}^{2}} \\
& h_{F S}^{2}=\frac{2 \sigma_{G C A}^{2}}{\sigma_{P h 1}^{2}}=\frac{2 \sigma_{G C A}^{2}}{2 \sigma_{G C A}^{2}+\sigma_{S C A}^{2}+\frac{\sigma_{p}^{2}}{r}+\frac{\sigma_{w}^{2}}{r n}}
\end{aligned}
$$

GCA effects were estimated following the methods reported by Griffing (1956b). Differences between GCA effects were tested using a Student's t-test.
Genetic correlations were calculated from the GCA covariance component of two characters in the numerator and the square root of the product of their GCA variance components in the denominator (Xiang et al. 2003a).

\section{The half-sib progeny}

The statistical analysis was based on individual tree measurements using the following mathematical model (Nanson 2004 eqn. 8):

$$
Y_{i j k}=\mu+B_{i}+F_{j}+F B_{j i}+e_{i j k}
$$

where $Y_{i j k}$ is the performance of the $k^{\text {th }}$ seedling in the $j^{\text {th }}$ family in the $i^{\text {th }}$ repetition, $\mu$ is the overall mean, $B_{i}$ is the effect of the $i^{\text {th }}$ repetition, $F_{j}$ is the effect of the $j^{\text {th }}$ family, $F B_{j i}$ is the interaction of the $j^{\text {th }}$ family and $i^{\text {th }}$ repetition, and $e_{\mathrm{ijk}}$ is the random error associated with the $i j k^{\text {th }}$ seedling.

The analyses of variance components were performed using the SPSS ${ }^{\circledast}$ software program ver. 19 (Univariate GLM \& VARCOMP). The assumptions of the model were checked by the Shapiro \& Wilk test for normality and by the Levene's test for homogeneity. The family effects were assumed to be random and were associated with the average genetic effects of the OP families. We considered OP families as true half-sib families and, consequently (eqn. 9):

$$
\sigma_{A}^{2}=4 \sigma_{F}^{2}
$$

where $\sigma_{A}^{2}$ is the additive genetic variance and $\sigma_{F}^{2}$ is the family variance. The narrowsense individual $\left(h_{i}^{2}\right)$ and half-sib family heritabilities $\left(h^{2}{ }_{\mathrm{HS}}\right)$ were calculated by the following formulas (Nanson 2004 - eqn. 10, eqn. 11):

$$
\begin{aligned}
& h_{i}^{2}=\frac{\sigma_{A}^{2}}{\sigma_{P h 1}^{2}}=\frac{4 \sigma_{F}^{2}}{\left(\sigma_{F}^{2}+\sigma_{F B}^{2}+\sigma_{e}^{2}\right)} \\
& h_{H S}^{2}=\frac{\sigma_{F}^{2}}{\sigma_{P h 2}^{2}}=\frac{\sigma_{F}^{2}}{\sigma_{F}^{2}+\frac{\sigma_{F B}^{2}}{r}+\frac{\sigma_{w}^{2}}{r n}}
\end{aligned}
$$

\begin{tabular}{|c|c|c|c|c|c|c|c|}
\hline \multirow{2}{*}{ Progeny } & \multirow{2}{*}{$\begin{array}{l}\text { Source of } \\
\text { variation }\end{array}$} & \multirow{2}{*}{ df } & \multicolumn{5}{|c|}{ Evaluations / Mean squares } \\
\hline & & & $\mathrm{I}-2012$ & II-2012 & III-2012 & IV-2012 & $\mathrm{I}-2013$ \\
\hline \multirow[t]{4}{*}{ Full-sib } & GCA & 10 & $1.087^{* * *}$ & $4.054^{* * *}$ & 3.520 & 6.047 & $5.454^{*}$ \\
\hline & SCA & 44 & $0.282^{* * *}$ & $1.034^{* * *}$ & $2.487^{* * *}$ & $3.784^{* * *}$ & $2.498^{* * *}$ \\
\hline & Error & 100 & 0.021 & 0.049 & 0.175 & 0.087 & 0.115 \\
\hline & $\begin{array}{l}\text { Within-plot } \\
\text { error }\end{array}$ & 3663 & 0.129 & 0.416 & 0.603 & 0.523 & 1.542 \\
\hline \multirow{4}{*}{$\begin{array}{l}\text { Open- } \\
\text { pollinated }\end{array}$} & Replication & 2 & 0.205 & 0.019 & 0.137 & 0.015 & 0.017 \\
\hline & Family & 5 & 0.004 & $2.546^{* * *}$ & $6.310^{* * *}$ & $3.791^{* * *}$ & $9.393^{* * *}$ \\
\hline & $\begin{array}{l}\text { Family } \times \\
\text { replication }\end{array}$ & 10 & 0.219 & 0.126 & 0.400 & 0.072 & 0.244 \\
\hline & Error & 254 & 0.004 & 0.094 & 0.448 & 0.457 & 1.428 \\
\hline
\end{tabular}

where $\sigma_{\mathrm{Ph} 1}^{2}$ and $\sigma_{\mathrm{Ph} 2}^{2}$ are the phenotypic variances; $\sigma_{A}^{2}$ is the additive genetic variance; $\sigma_{\mathrm{F}}^{2}$ is the family variance; $\sigma_{\mathrm{FB}}^{2}$ is the

Tab. 1 - Analysis of variance for bud flushing in the nursery tests. (1-2012): the first evaluation in the year 2012; (II-2012): the second evaluation in the year 2012; etc. (*): $p<$ $0.05 ;(* *): p<0.001$. family $\times$ repetition interaction variance; $\sigma_{\mathrm{e}}^{2}$ $=\sigma_{\mathrm{p}}^{2}+\sigma_{\mathrm{w}}^{2} / \mathrm{n} ; \sigma_{\mathrm{p}}^{2}$ is the variance among plots; $\sigma_{w}^{2}$ is the within-plot variance; $n$ is the number of seedlings per plot; and $r$ is number of repetitions.

Standard errors for heritability were estimated according to Dickerson (1969) by assuming that the denominator is a constant. Genetic correlations were calculated from the additive genetic covariance of two traits, $\mathrm{X}$ and $\mathrm{Y}$, in the numerator and the square root of the product of their additive genetic variances in the denominator (Falconer \& Mackay 1996). Pearson's correlations based on family means were also calculated to examine relationships between traits, generated by $\mathrm{CCs}$ and $\mathrm{OP}$, and whether the observed differences in flushing reactions are correlated to the geographic coordinates and the climatic conditions of the parents' origin (LAT: latitude; LONG: longitude; ALT: elevation, in $m$ a.s.I.; TMA: mean annual temperature; PMA: mean annual precipitation calculated for the period of 1968-1977).

\section{Results}

\section{Genetic variation and variance components}

Mean squares estimates for bud flushing evaluations derived from each of the mating designs are presented in Tab. 1. The diallel analysis highlighted very significant ( $p$ $<0.001$ ) differences among parents regarding GCA in both the 2012 and 2013 growing seasons. Also, there were highly significant $(p<0.001)$ differences among families with respect to SCA for all evaluations of bud flushing. Therefore, both GCA and SCA effects were very important sources of variation for this trait.

For OP progenies, the analysis of variance also revealed highly significant $(p<0.001)$ differences among half-sib families for bud flushing in the two years of observations.

In 2012, the first assessment of bud flushing was performed on 30 April, when average percentages of bud flushing were $10 \%$ in CC progeny and 3\% in OP progeny, and continued every five days until 15 May. In 2013, the bud flushing evaluation was 
Tab. 2 - Estimates of averages, phenotypic variances and heritabilities. $\left(\sigma_{\text {Ph1 }}^{2}, \sigma_{\text {Ph2 }}^{2}\right)$ : phenotypic variances; $\left(h^{2}\right)$ : narrow-sense individual heritability; $\left(h_{\mathrm{FS}}^{2}\right)$ : full-sib family heritability; $\left(h_{\mathrm{HS}}^{2}\right)$ : half-sib family heritability.

\begin{tabular}{|c|c|c|c|c|c|c|}
\hline \multirow{2}{*}{ Progeny } & \multirow{2}{*}{$\begin{array}{l}\text { Genetic } \\
\text { parameters }\end{array}$} & \multicolumn{5}{|l|}{ Evaluations } \\
\hline & & $\mathrm{I}-2012$ & II-2012 & III-2012 & IV-2012 & I-2013 \\
\hline \multirow[t]{5}{*}{ Full-sib } & Mean & 1.10 & 1.75 & 3.14 & 4.06 & 3.21 \\
\hline & $\sigma_{\mathrm{Ph} 1}^{2}$ & 0.585 & 2.104 & 3.294 & 4.788 & 4.543 \\
\hline & $\sigma_{\mathrm{Ph} 2}^{2}$ & 0.449 & 1.681 & 2.611 & 4.239 & 3.078 \\
\hline & $h_{i}^{2}$ & $0.612 \pm 1.401$ & $0.638 \pm 1.013$ & $0.139 \pm 0.277$ & $0.210 \pm 0.201$ & $0.289 \pm 0.375$ \\
\hline & $h_{\mathrm{FS}}^{2}$ & $0.398 \pm 0.456$ & $0.399 \pm 0.317$ & $0.088 \pm 0.087$ & $0.119 \pm 0.057$ & $0.213 \pm 0.138$ \\
\hline \multirow[t]{5}{*}{ Open-pollinated } & Mean & 1.00 & 1.17 & 3.13 & 4.20 & 2.99 \\
\hline & $\sigma_{\mathrm{Ph} 1}^{2}$ & 0.024 & 0.247 & 0.592 & 0.573 & 1.730 \\
\hline & $\sigma_{\mathrm{Ph} 2}^{2}$ & 0.010 & 0.061 & 0.152 & 0.109 & 0.280 \\
\hline & $h_{i}^{2}$ & $0.837 \pm 1.634$ & $0.934 \pm 2.114$ & $0.950 \pm 1.740$ & $0.618 \pm 1.780$ & $0.503 \pm 1.039$ \\
\hline & $h_{\mathrm{HS}}^{2}$ & $0.495 \pm 0.968$ & $0.950 \pm 2.151$ & $0.923 \pm 1.718$ & $0.815 \pm 2.348$ & $0.778 \pm 1.605$ \\
\hline
\end{tabular}

made on 8 May, and bud flushing percentages were $88 \%$ in CC progeny and $81 \%$ in OP progeny. On average, the OP flushing index was smaller than the $C C$ index. These differences could be assigned to paternal heredity, which is unknown in OP progeny.

In CC experiments, the earliest clones were 5 and 544, whose percentages of flushing at the first evaluation were 40$50 \%$. They started bud flushing after seven consecutive days with temperatures higher than $10{ }^{\circ} \mathrm{C}$. The differences in days among the earliest clones and the latest clone (376, 421 and 134) were 5 days. In OP experiments, the earliest clones were also 5 , 371 and 145 and the latest 134 and 138.

Variance component estimates, their standard errors, dominance-to-additive ra- tios for CC and OP progenies are listed in Tab. S2 (Supplementary material). Thus, in CC experiments, the dominance variance $\left(\sigma_{\text {SCA }}^{2}\right)$ exerted a greater influence on this trait, as evidenced by the $\sigma_{\text {SCA }}^{2} / \sigma_{C C A}^{2}$ ratio for all evaluations. The $\sigma_{S C A}^{2} / \sigma_{C C A}^{2}$ ratio ranged from 2.9 to 20.1 , depending on the bud development stage. The additive genetic variance represented $6-25 \%$ of the phenotypic variance. The highest values of additive genetic variance were obtained during the first half of the assessment periods (CC-I-2012, CC-II-2012, CC-2013), when GCA also differed considerably between parents.

In the case of OP progenies, the additive genetic variance $\left(\sigma_{A}^{2}\right)$ was greater than that of CC progenies, representing $50-95 \%$

Tab. 3 - General combining ability (GCA) effects for 11 parents in silver fir half-diallel. (CC-I-2012): the bud flushing score in the full-sib progeny of the first evaluation in the year 2012; (CC-II-2012): the bud flushing score in the full-sib progeny of the second evaluation in the year 2012, etc. $(*): p<0.05 ;(* *): p<0.01 ;(* *): p<0.001$.

\begin{tabular}{rccccc}
\hline Clone & CC-I-2012 & CC-II-2012 & CC-III-2012 & CC-IV-2012 & CC-I-2013 \\
\hline 5 & $0.382^{* * *}$ & $0.705^{* * *}$ & $0.466^{* *}$ & 0.447 & $0.517^{*}$ \\
544 & $0.249^{* * *}$ & $0.398^{*}$ & 0.323 & 0.506 & 0.445 \\
50 & 0.018 & 0.054 & -0.075 & -0.193 & 0.067 \\
541 & -0.043 & 0.074 & 0.152 & -0.015 & 0.089 \\
371 & 0.053 & 0.262 & 0.289 & 0.379 & 0.312 \\
35 & 0.018 & -0.025 & 0.101 & 0.260 & 0.067 \\
138 & -0.072 & -0.302 & 0.059 & 0.346 & 0.188 \\
376 & $-0.220^{* * *}$ & $-0.385^{*}$ & $-0.557^{* *}$ & $-0.665^{*}$ & $-0.664^{* *}$ \\
145 & -0.057 & -0.099 & -0.033 & -0.193 & -0.268 \\
421 & $-0.198^{* * *}$ & -0.325 & -0.493 & $-0.691^{*}$ & $-0.713^{* *}$ \\
134 & $-0.131^{* *}$ & -0.358 & -0.232 & -0.181 & -0.041 \\
\hline
\end{tabular}

of the phenotypic variance. The highest values were also obtained for the start of the growing period.

\section{Genetic parameters}

The values of the heritability coefficients based on the CC and OP progenies are listed in Tab. 2. Narrow-sense individual heritability estimates for CC progenies ranged from 0.139 to 0.638 , while the fullsib family heritability ranged from 0.088 to 0.398. In the OP progenies, the values of individual and family heritabilities were higher than in the CC progeny and ranged from 0.495-0.950. In both experiments, heritabilities were higher for bud flushing at the beginning of the growing period ( $\mathrm{I}$ 2012, II-2012) than at later stages.

GCA effects were calculated for each parent from the diallel design (Tab. 3). Both positive and negative significant effects ( $p$ $<0.001$ ) were found for this phenological trait. Therefore, the parents in this experiment could be separated into three categories: early flushing, late flushing and intermediary.

Genetic correlations between analysed traits in CC experiment are shown in Tab. 4. High additive genetic correlations were obtained between bud flushing stages evaluated in the spring of 2012 and 2013. The genetic correlations between bud flushing and growth traits were positive and very significant only for D-2012, D-2013 and H2012. Significant correlations between current height increment in 2012 and 2013, and bud flushing was not found.

In OP progenies, significant genetic corre-

Tab. 4 - Trait-trait additive genetic correlations and phenotypic correlations with geographic coordinates of the parent for full-sib progeny. (H-2012, H-2013): total height at the ages of 5 and 6; (h-2012, h-2013): current height increment at ages of 5 and 6; (D-2012, D-2013): root collar diameter at the ages of 5 and 6; (LAT): latitude; (LONG): longitude; (ALT): elevation. $(*): p<0.05 ;(* *): p<0.01$; $(* * *): p<0.001$

\begin{tabular}{|c|c|c|c|c|c|c|c|c|c|c|}
\hline Traits & CC-I-2013 & H-2012 & H-2013 & h-2012 & h-2013 & D-2012 & D-2013 & LAT & LONG & ALT \\
\hline CC-I-2012 & $0.328^{*}$ & -0.002 & -0.057 & -0.030 & -0.108 & 0.174 & 0.088 & -0.225 & 0.240 & -0.441 \\
\hline CC-II-2012 & $0.309^{*}$ & -0.052 & -0.083 & -0.035 & -0.112 & 0.097 & 0.055 & -0.327 & 0.078 & $-0.558^{*}$ \\
\hline CC-III-2012 & $0.600^{* * *}$ & $0.335^{*}$ & 0.184 & 0.176 & 0.051 & $0.665^{* * *}$ & $0.456^{* * *}$ & -0.078 & 0.252 & -0.348 \\
\hline CC-IV-2012 & $0.522^{* * *}$ & $0.437^{* * *}$ & 0.252 & 0.190 & 0.091 & $0.739^{* * *}$ & $0.498^{* * *}$ & -0.012 & 0.236 & -0.256 \\
\hline CC-I-2013 & - & $0.352^{* *}$ & 0.212 & 0.196 & 0.091 & $0.597^{* * *}$ & $0.388^{* *}$ & -0.066 & 0.281 & -0.339 \\
\hline
\end{tabular}


Tab. 5 - Phenotypic correlations among traits and geographic coordinates of the parent for half-sib progeny. (OP-I-2012): bud flushing score in the open-pollinated progeny of the first evaluation in the year 2012; (OP-II-2012): bud flushing score in the open-polli nated progeny of the second evaluation in the year 2012, etc.; (LAT): latitude; (LONG): longitude; (ALT): elevation. $\left({ }^{*}\right): p<0.05 ;(* *)$ : $p<0.01 ;(* * *): p<0.001$.

\begin{tabular}{lcccccccccc}
\hline Traits & OP-I-2013 & CC-I-2012 & H-2012 & H-2013 & h-2012 & D-2012 & D-2013 & LAT & LONG & ALT \\
\hline OP-I-2012 & $0.760^{*}$ & $0.929^{* * *}$ & -0.394 & -0.131 & -0.138 & 0.156 & 0.144 & -0.605 & 0.178 & -0.581 \\
OP-II-2012 & 0.359 & 0.168 & -0.104 & -0.458 & -0.049 & 0.328 & 0.650 & -0.322 & $-0.976^{* * *}$ & -0.109 \\
OP-III-2012 & $0.678^{*}$ & 0.343 & -0.635 & -0.622 & $-0.723^{*}$ & $-0.775^{*}$ & -0.484 & 0.531 & 0.122 & 0.536 \\
OP-IV-2012 & 0.563 & 0.106 & $-0.803^{*}$ & $-0.751^{*}$ & $-0.834^{* *}$ & $-0.910^{* *}$ & -0.576 & 0.388 & 0.367 & 0.347 \\
OP-I-2013 & - & $0.852^{* *}$ & - & 0.412 & - & - & 0.548 & $-0.805^{*}$ & -0.396 & $-0.702^{*}$ \\
\hline
\end{tabular}

lations between bud flushing and growth traits were not found; for this reason, phenotypic correlations are presented in Tab. 5 instead. Negative phenotypic correlations between bud flushing and height, root collar diameter and current height increment were obtained. Significant correlations also were highlighted between bud flushing stages evaluated in OP progenies and CC progenies, indicating a maternal genetic control of this trait.

In both OP and CC progenies, bud flushing was negatively correlated with altitude ( $r$ ranged from -0.702 to -0.109) of the location of origin of the plus trees. Correlations with longitude and latitude were also negative and were found for the OP family only. Correlations with altitude and latitude were low but significant $(p<0.05)$, which indicates that trees from lower altitudes and southern latitudes open their buds earlier than trees from northern latitudes and higher altitudes. The correlation with longitude of the origin of plus trees was stronger $(r=-0.98)$.

Bud flushing variation at the family level was related to geographic and climatic parameters of the parents' origin (LAT, LONG, ALT, TMA, PMA) by multiple regression analysis. For CC-II-2012 and OP-II-2012, the models were significant, accounting for $83 \%$ and $97 \%$, respectively, of the total variation of these traits (Tab. $\mathrm{S}_{3}$ in Supplementary material).

\section{Discussion}

Bud burst and bud set are important adaptive traits, because they determine the co-adaptation of the vegetation period of trees to the periodic variation of the climatic components of the environment where trees live (Falkenhagen 1977). In this study, because the dates for bud set were not monitored, the average season length could not be determined.

European silver fir has a high degree of variation within populations (Konnert \& Bergmann 1995, Teodosiu 2009). The large non-additive variance for bud flushing, as well as for growth traits, is in agreement with the genetic system of European silver fir. From a practical standpoint, these results indicate that bud flushing of European silver fir is under genetic control and provides information on family, within-family and parental selection. In a breeding programme, individuals that start later in terms of vegetation are of interest, because they are not harmed by late spring frosts. Our results are in agreement with data published by Hansen \& Larsen (2004), who found significant variation among European silver fir provenances concerning the bud-burst and a positive correlation between the resistance to winter frost and the later bud burst.

Individual and family heritability estimates in CC progenies differ comparatively with those obtained in OP progenies. For the first two evaluations, which refer to the beginning of the growing season, the differences between CC and OP estimates varied from 36 to $46 \%$ for individual heritability and from 24 to $38 \%$ for family heritability. OP estimates of additive genetic variance and heritability were greater than estimates of these parameters in CC progenies. Although the parameters do not differ significantly from each other at the 0.05 level, we should interpret OP estimates with caution. The differences between genetic parameters obtained in CC and OP progenies could be explained by violation of the true half-sib assumption (an intraclass correlation coefficient of 0.25 ) or by different male parents involved in the two experiments. The high heritabilities we observed for bud flush dates agree with the results found in other species (Aitken \& Adams 1997, Hannerz et al. 1999).

The correlations among bud flushing determined in CC progeny and in OP progeny were positive and significant, which proves a maternal effect of heredity of this trait. In order to establish both species breeding strategies and the rules for transfer of forest reproductive material, the correlations between bud flushing and growth traits should be known. To safeguard trees against late spring frost and early fall frost, superior growth potential should be independent of shoot phenology and duration of the growing season (Rweyongeza et al. 2010). Overall, we found significant correlations between phenology and growth in both experiments but in different directions. In CC progeny, the genetic correlations between bud phenology and growth performance were positive and significant only for root collar diameter (D-2012, D2013) and $\mathrm{H}-2012$. This means the seedlings that flushed earlier had a higher growth rate. Non-existent correlations with annual height increment could be explained by the fact that they were assessed only on the date of bud flushing initiation and not throughout the growing season. However, this does not preclude the dependence of the annual height increment on the length of the growing season.

In OP progeny, significant genetic correlations between bud phenology and growth performances were not obtained, but phenotypic correlations were negative for growth traits assessed in the 2012 growing season and with $\mathrm{H}-2013$. Studies of other species, such as white spruce, indicated that growth potential was negatively related to shoot phenology ( Li et al. 1993). In Norway spruce, Sonesson \& Eriksson (2003) observed a low correlation between the time of bud flushing and the height increment in the second growing season. Further, different stages of bud flushing in Norway spruce were slightly negatively correlated genetically with 9-14 year-old field heights (Hannerz et al. 1999). Genetic correlations between phenological traits and growth traits in Pinus brutia (Kaya \& Isik 1997) were negative in most cases and not very strong, indicating that those seedlings with high growth performance are not necessarily the ones with a longer growing season. The diameter of Douglas fir can be effectively increased by simultaneously selecting for later bud burst, because these traits are uncorrelated in studied populations (Schermann et al. 1997).

The genetic material in both $\mathrm{CC}$ and $\mathrm{OP}$ experiments consists of progeny of plus trees originating from different latitudes, longitudes and altitudes, tested in a seed orchard. The correlations indicated some geographic clines for bud phenology of European silver fir. Indeed, in both CC and OP progenies, negative significant correlations with the altitude of the location of origin of plus trees were obtained. Significant correlations with latitude and longitude were found only in OP families. Further, trees originating from southern latitudes and western longitudes are characterised by an earlier onset of bud flushing. Latitude, longitude, altitude, TMA and PMA were found to be statistically significant explanatory variables for bud flushing.

Provenance studies also indicated a variable pattern of phenological traits of European silver fir with geographic coordinates of the place of origin (Vitasse et al. 2009). Such geographic variation of the European 
silver fir populations could be the result of local adaptation to different climatic conditions of the location of origin. The differences in terms of climate between the south-western (Mediterranean) and the north-eastern (semi-arid) regions of Romania (Birsan 2015) can significantly influence the adaptive traits of species. Long-term climatic changes throughout Romania are well documented in various recent papers. Climatic changes in Romania since 1961 show increasing temperatures in all seasons except autumn (Dumitrescu et al. 2015).

Relationships among variation of bud flushing and geographic coordinates also were observed in other species, such as Picea sitchensis (Falkenhagen 1977), Picea glauca (Li et al. 1993), Picea abies (Leinonen \& Hanninen 2002), Pinus sylvestris (Andersson \& Fedorkov 2004) and Fagus sylvatica (Chmura \& Rozkowski 2002). The patterns of variation varied with species, some exhibiting positive correlations, others showing negative correlations.

Our findings revealed a high genetic control of bud flushing of European silver fir, whereby a large genetic gain can be obtained in future breeding generations. Selections at the genitor as well as family levels will increase the genetic gain during the breeding programme.

\section{Acknowledgements}

This work was realised within the framework of the GENCLIM project ("Evaluating the adaptive genetic potential of the main coniferous species for sustainable forest management in the context of climate change") financed by the Romanian Executive Agency for a Higher Education, Research, Development and Innovation Funding, grant number PN-II-PC-PCCA-2013-40695. The authors also thank the anonymous reviewers for their useful comments and advice.

\section{References}

Aitken SN, Adams WT (1997). Spring cold hardiness under strong genetic control in Oregon populations of Pseudotsuga menziesii var. menziesii. Canadian Journal of Forest Research 27: 1773-1780. - doi: 10.1139/x97-151

Andersson B, Fedorkov A (2004). Longitudinal differences in Scots pine frost hardiness. Silvae Genetica 53 (2): 76-80. - doi: 10.1515/sg-2004-00 14

Bailey JD, Harrington CA (2006). Temperature regulation of bud-burst phenology within and among years in a young Douglas fir (Pseudotsuga menziesii) plantation in western Washington, USA. Tree Physiology 26 (4): 421-430. - doi: 10.1093/treephys/26.4.421

Barzdajn W (2010). Provenance and family variation of silver fir (Abies alba Mill.) in the experiment established in the Siemianice Forest Experimental Station in 1996. Annals of Warsaw University of Life Sciences - SGGW, Forestry and Wood Technology 73: 51-64.

Becker WA (1967). Manual of procedures in quantitative genetics ( $2^{\text {nd }}$ edn). Academic En- terprise, Pullman, WA, USA, pp. 124. Birsan MV (2015). Trends in monthly natural streamflow in Romania and linkages to atmospheric circulation in the North Atlantic. Water Resources Management 29 (9): 3305-3313. - doi: 10.1007/s11269-015-0999-6

Chmura DJ, Rozkowski R (2002). Variability of beech provenances in spring and autumn phenology. Silvae Genetica 51 (2-3): 123-127.

Dhar A, Balliet N, Hawkins CDB, Carlson MR, Berger VG, Mahoney R (2015). Bud flush phenology and nursery carryover effect of paper birch provenances. iForest 8: 809-817. - doi: 10.3832/ ifor1367-008

Dickerson GE (1969). Techniques for research in quantitative animal genetics. Techniques and Procedures in Animal Science Research, American Society of Animal Science, New York, NY, USA, pp. 36-79.

Ducci F, De Cuyper B, Pâques LE, Proietti R, Wolf $H$ (2012). Reference protocols for assessment of trait and reference genotypes to be used as standards in international research projects. Ed. CRA SEL, Arezzo, Italy, pp. 82. [online] URL: http://www.researchgate.net/publication/30178 9853

Dumitrescu A, Birsan MV (2015). ROCADA: a gridded daily climatic dataset over Romania (19612013) for nine meteorological variables. Natural Hazards 78 (2): 1045-1063. - doi: 10.1007/s11069015-1757-z

Dumitrescu A, Bojariu R, Birsan MV, Marin L, Manea $A$ (2015). Recent climatic changes in Romania from observational data (1961-2013). Theoretical and Applied Climatology 122 (1-2): 111-119. doi: 10.1007/s00704-014-1290-0

Emerson JL, Frampton J, McKeand SE (2006). Genetic variation of spring frost damage in 3year-old Fraser fir Christmas tree plantations. HortScience 41 (7): 1531-1536. [online] URL: http://hortsci.ashspublications.org/content/41/7 /1531.short

Eriksson G, Ekberg I, Dormling I, Matern B (1978). Inheritance of bud-set and bud-flushing in Picea abies (L.) Karst. Theoretical and Applied Genetics 52: 3-19. - doi: 10.1007/BFo0273761

Falconer DS, Mackay TFC (1996). Introduction to quantitative genetics ( $4^{\text {th }}$ edn). Longman and Co., Harlow, NY, USA, pp. 360.

Falkenhagen ER (1977). Genetic variation in 38 provenances of Sitka spruce. Silvae Genetica 26 (2-3): 67-75.

Gagov V, Evtimov I, Zhelev P (2005). Comparative study on the growth of half-sib families of selected trees of Abies alba (Mill.) and Abies borisii-regis (Mattf.) from Bulgarian and Macedonian provenances. In: Proceedings of the " $11^{\text {th }}$ International Silver Fir Symposium". Poiana Brasov (Romania) 4-9 Sept 2005. ICAS, Brasov, Romania, pp. 23.

Gauchata ME, Pâques LE (2011). Indirect prediction of bud flushing from ex situ observation in hybrid larch (Larix decidua $\times$ L. kaempferi) and their parents. Environmental and Experimental Botany 70: 121-130. - doi: 10.1016/j.envexpbot.20 10.08.001

Gomory D, Paule L (2011). Trade-off between height growth and spring flushing in common beech (Fagus sylvatica L.). Annals of Forest Science 68: 975-984. - doi: 10.1007/s13595-011-0103-
Griffing B (1956a). A generalized treatment of the use of diallel crosses in quantitative inheritance. Heredity 10: 31-50. - doi: 10.1038/hdy.19 56.2

Griffing B (1956b). Concept of general and specific combining ability in relation to diallel crossing systems. Australian Journal of Biological Sciences 9: 463-493. - doi: 10.1071/Bl9560463 Hannerz M, Sonesson J, Ekberg I (1999). Genetic correlations between growth and growth rhythm observed in a short-term test and performance in long-term field trials of Norway spruce. Canadian Journal of Forest Research 29: 768-778. - doi: 10.1139/x99-056

Hansen JK, Larsen JB (2004). European silver fir (Abies alba Mill.) provenances from Calabria, southern Italy: 15-year results from Danish provenance field trials. European Journal of Forest Research 123: 127-138. - doi: 10.1007/s103 42-004-0031-9

Jones GE, Cregg BM (2006). Bud break and winter injury in exotic firs. HortScience 41: 143-148. Kaya Z, Isik F (1997). The pattern of genetic variation in shoot growth of Pinus brutia Ten. populations sampled from the Toros Mountains in Turkey. Silvae Genetica 46 (2-3): 73-81. [online] URL: http://pdfs.semanticscholar.org/feb7/b8a5 6215124f54e39a2fc01e1ef9c73b35ab.pdf Kerr G, Stokes V, Peace A, Jinks R (2015). Effects of provenance on the survival, growth and stem form of European silver fir (Abies alba Mill.) in Britain. European Journal of Forest Research 134: 349-363. - doi: 10.1007/s10342-0140856-9

Konnert M, Bergmann F (1995). The geographic distribution of genetic variation of silver fir in relation to its migration history. Plant Systematics and Evolution 196: 19-30. - doi: 10.1007/BF 00985333

Leinonen I, Hanninen $\mathrm{H}$ (2002). Adaptation of the timing of bud burst of Norway spruce to temperate and boreal climates. Silvae Fennica 36 (3): 695-701. [online] URL: http://www.mc it.stat.vtt.metla.eu/silvafennica/full/sf36/sf3636 95.pdf

Li P, Adams WT (1993). Genetic control of bud phenology in pole-sized trees and seedlings of coastal Douglas fir. Canadian Journal of Forest Research 23: 1043-1051. - doi: 10.1139/x93-133

Li P, Beaulieu J, Corriveau A, Bousquet J (1993). Genetic variation in juvenile growth and phenology in a white spruce provenance-progeny test. Silvae Genetica 42 (1): 53-60.

Mihai G (2009). Surse de seminte testate pentru principalele specii de arbori forestieri din Romania [Tested seed sources for the main forest species in Romania] (Mihai G ed). Editura Silvica, Bucharest, Romania, pp. 280. [in Romanian]

Mihai G, Mirancea I, Duta C (2014). Variation of the quantitative traits in a progeny test of Abies alba (Mill.) at the nursery stage. Silvae Genetica 63 (6): 275-284. - doi: 10.1515/sg-2014-00 35

Nanson A (2004). Genetique et amelioration des arbres forestieres [Genetics and tree breeding]. Les Presses Agronomique de Gembloux, Belgique, pp. 712. [in French]

Parnuta $\mathrm{GH}$, Lorent A, Tudoroiu M, Petrila $M$ (2010). Regiunile de provenienta pentru materialele de baza din care se obtin material for- 
estiere de reproducere din Romania [The provenance regions for the basic materials established in Romania]. Editura Silvica, Bucharest, Romania, pp. 122. [in Romanian]

Rweyongeza DM, Yeh FC, Dhir NK (2010). Genetic parameters for bud flushing and growth characteristics of white spruce seedlings. Silvae Genetica 59: 4.

Schaffer HE, Usanis RA (1969). General least squares analysis of diallel experiments. A computer program-DIALL. Genetic Dept Research Report no. 1, North Carolina State University, Raleigh, NC, USA, pp. 57.

Schermann N, Adams WT, Aitken SN, Bastien JCH (1997). Genetic parameters of stem form traits in a 9-year-old coastal Douglas fir progeny test in Washington. Silvae Genetica 46: 2-3. Sonesson J, Eriksson G (2003). Genetic variation in drought tolerance in Picea abies seedlings and its relationship to growth in controlled and field environments. Scandinavian Journal of Forest Research 18: 7-18. - doi: 10.1080/028275 81.2003.10383133

Steiner KC (1979). Patterns of variation in budburst timing among populations in several Pinus species. Silvae Genetica 28 (5-6): 185-193.
Teodosiu M (2009). Evaluating the genetic diversity of silver fir by isozyme gene markers. In: "Tested seed sources for the main forest species in Romania" (Mihai G eds). Editura Silvica, Bucharest, Romania, pp. 178-184.

Vitasse Y, Delzon S, Bresson C, Michalet R, Kremer A (2009). Altitudinal differentiation in growth and phenology among populations of temperate-zone species growing in a common garden. Canadian Journal of Forest Research 39: 1259-1269. - doi: 10.1139/Xo9-054

Von Wuehlisch G, Krusche D, Muhs HJ (1995). Variation in temperature sum requirement for flushing of beech provenances. Silvae Genetica 44 (5-6): 343-346.

Worrall J (2008). Temperature effects on bud burst and leaf fall in subalpine larch. Journal of Sustainable Forestry 1 (2): 1-18. - doi: 10.1300/ Jo91v01no2_01

Wu HX, Matheson AC (2000). Analysis of halfdiallel mating design with missing crosses: theory and SAS program for testing and estimating GCA and SCA fixed effects. Silvae Genetica 49: 130-137. [online] URL: http://www.sauer laender-verlag.com/CMS/fileadmin/content/do kument/archiv/silvaegenetica/49_2000/49-3- 130.pdf

Xiang B, Li B, Isik F (2003a). Time trend of genetic parameters in growth traits of Pinus taeda L. Silvae Genetica 52 (3): 114-121. [online] URL: http://www.thuenen.de/media/institute/f g/PDF/Silvae_Genetica/2003/Vol._52_Heft_3-4/ 52 3-4_114.pdf

\section{Supplementary Material}

Tab. S1 - Analysis of variance of the halfdiallel and expected mean squares (Griffing 1956a).

Tab. S2 - Variance components and their standard errors for bud flushing in full-sib and open-pollinated progenies.

Tab. S3 - Regression equations and associated $\mathrm{R}^{2}$ values for bud flushing with geographic and climatic parameters of the parental location of origin.

Link: Mihai_2314@supploo1.pdf 